\title{
É inerente ao ser humano! A naturalização das hierarquias sociais frente às expressões de preconceito e discriminação na perspectiva juvenil
}

\author{
| ${ }^{1}$ Simone Souza Monteiro, ${ }^{2}$ Wilza Vieira Villela, ${ }^{3}$ Priscilla da Silva Soares I
}

Resumo: Este trabalho objetiva analisar como mulheres e homens jovens, com diferentes inserções sociais, cor/raça e orientação sexual, frequentadores de espaços de sociabilidade no Rio de Janeiro, concebem e vivenciam as expressões de preconceito e discriminação na vida cotidiana. Considerase que o preconceito e a discriminação fazem parte de um processo social de produção de desigualdades que articula diferentes marcadores sociais (classe social, gênero, sexualidade, raça/etnia) e opera por meio da naturalização dos atos de discriminar e de ser discriminado. Todavia, há perspectivas teóricas dissonantes, que concebem a discriminação e o preconceito como decorrentes de interações inerentes e circunscritas ao âmbito das relações sociais interpessoais, desvinculadas dos fatores macrossociais. Os depoimentos dos/das jovens do estudo revelam que os agentes da ação discriminatória evitam falar de preconceito, justificando suas práticas com base no gosto, preferência ou estranhamento frente a algo incomum. Entretanto, alguns sujeitos que são objeto de ações homofóbicas, sexistas e/ou racistas percebem que essas situaçōes expressam uma tentativa de garantia de privilégios de grupos específicos e que a classe social dos envolvidos tem influência nessas manifestações. Outros consideram que a homofobia e o racismo resultam da falta de conhecimento e/ou socialização. Observa-se a ausência de referências à ação política para confrontar situações de discriminação. O desenvolvimento de estudos voltados para a apreensão do preconceito e da discriminação como fenômenos sociais complexos, associados à (re) produção de marcadores sociais da diferença, podem orientar as ações de enfrentamento desses processos em diferentes contextos sociais.

> Palavras-chave: discriminação; preconceito; diversidade sexual; cor/raça; juventude.

http://dx.doi.org/10.1590/S0103-73312014000200006

\author{
1 Laboratório de Educação em \\ Ambiente e Saúde do Instituto \\ Oswaldo Cruz, Fundação \\ Oswaldo Cruz. Rio de Janeiro, \\ Brasil. Endereço eletrônico: \\ msimone@ioc.fiocruz.br \\ 2 Programa de Pós Graduação \\ em Promoção da Saúde, \\ Universidade de Franca; \\ Programa de Pós Graduação \\ em Saúde Coletiva, UNIFESP. \\ São Paulo, Brasil. Endereço \\ eletrônico: wilza.villela@gmail. \\ com \\ ${ }^{3}$ Laboratório de Educação em \\ Ambiente e Saúde, Instituto \\ Oswaldo Cruz, Fiocruz. Rio \\ de Janeiro, Brasil.Endereço \\ eletrônico: priscillasoares@ \\ terra.com.br
}

Recebido em: 14/06/2013 Aprovado em: 17/04/2014 
Este artigo objetiva analisar como mulheres e homens jovens, com diferentes inserções sociais, cores/raça e orientação sexual, concebem e vivenciam a discriminação e o preconceito na vida cotidiana. $\mathrm{O}$ trabalho toma como referência as variadas apropriações dos conceitos de estigma, discriminação e preconceito pela produção acadêmica no campo das ciências sociais e da saúde e suas implicações para as formas de enfrentamento dos processos de estigmatização (LINK; PHELAN, 2001).

Em trabalhos anteriores, foi possível constatar a utilização da teorização de E. Goffman (1963) acerca do estigma na literatura internacional e nacional sobre Aids e saúde (MAHAJAN et al., 2008; PARKER, 2012; MONTEIRO et al., 2013; MONTEIRO et al, 2012; ARMIJO et al, 2008; SILVA et al, 2013). Para esse autor, o estigma é definido como a atribuição de um valor negativo a uma dada característica do sujeito, que assim é transformada em marca de uma suposta inferioridade. A conexão estabelecida entre aspectos físicos ou comportamentais e atributos morais pejorativos alimenta manifestações de repúdio aos indivíduos ou grupos possuidores destas "marcas".

O uso do termo "preconceito" é mais recorrente nos estudos sobre racismo e tem como referência conceitual o trabalho de Allport (1954), no qual o preconceito é descrito como atitude hostil ou aversiva dirigida a uma pessoa ou grupo que tenha qualidades consideradas censuráveis socialmente. Para o autor, a consequência do preconceito é posicionar um indivíduo ou grupo de forma desvantajosa em função de crenças, comportamentos ou outras características que o diferenciem dos grupos dominantes num determinado contexto social. ${ }^{1}$

A atribuição valorativa ou moral depreciativa aos sujeitos em função de características corporais, que resulta em processos de estigmatização, tem sido problematizada em pesquisas sociais sobre desigualdades de gênero e cor/raça (STOLCKE, 1991; GUIMARÃES, 2004; SANSONE, 2004; FRY, 2005; MONTEIRO; CECCHETTO, 2009). Tais discussões assinalam as implicações da ideia de naturalização na qual um evento social é considerado efeito da "natureza" e apontam para as relações de poder e hierarquias das estruturas sociais envolvidas nos processos de produção de estigmas.

Embora os temas e campos disciplinares nos quais se originam os estudos sobre estigma, discriminação e preconceito apresentem especificidades teóricometodológicas, interessa destacar a forte tendência de apropriação do conceito 
de estigma como uma marca indesejável do sujeito. Trabalhos baseados nesta perspectiva tendem a privilegiar a percepção dos sujeitos sobre os processos de estigmatização e suas consequências para as interações sociais. $\mathrm{O}$ fato de grande parte desses estudos, principalmente no campo da saúde, tomar esses processos como resultado de relações interpessoais, elide o reconhecimento de que essas ocorrências no âmbito microssocial reproduzem dinâmicas sociais de exclusão e desigualdade situadas em âmbito macrossocial (LINK; PHELAN, 2001; PARKER; AGGLETON, 2003). Ou seja, o foco nas interações interpessoais limita o reconhecimento da função social do estigma, da discriminação e do preconceito na produção e manutenção das desigualdades entre os indivíduos e grupos sociais, bem como reduz a compreensão dos processos de naturalização das diferenças e hierarquias sociais.

A naturalização de fatos sociais pode ser descrita como comportando três movimentos: num primeiro, um grupo pretende obter privilégios em relação a outro; num segundo, é acionada uma estratégia de desqualificação do sujeito, a partir da escolha arbitrária de alguma característica corporal como marca da sua insuficiência; num terceiro, esta característica é apontada como causa da insuficiência, de tal modo que o sujeito se torna inexoravelmente situado numa posição de inferioridade. Nesta perspectiva, o corpo é tomado como expressão essencial do sujeito, materialidade que determina comportamentos e configura seu estatuto moral. Operação semelhante ocorre quando o que é tomado como a marca que justifica o estigma não é uma característica corporal, e sim uma prática social não hegemônica, como relações sexuais com pessoas do mesmo sexo. Neste caso, uma prática social específica é tomada como expressão de um traço moral negativo, entendido como constitutivo do sujeito e como justificativa para seu alijamento social.

Parte da eficácia do processo de naturalização das desigualdades sociais reside na crença de um suposto substrato "natural" dos sujeitos, irredutível às operações da linguagem ou da ação humana, que confere às características demarcadoras da inferioridade de alguns sujeitos um sentido de contingência. A exclusão do acesso a bens materiais e simbólicos dos que possuem estas características seria uma consequência "natural" de sua inferioridade constitutiva, sobre a qual não cabem dúvidas ou questionamentos; sendo assim, a exclusão ou marginalização social não é percebida como uma tradução de processos sociais para as relações 
interpessoais, operada por meio da ideologia e de diferentes práticas sociais (GATO et al., 2011).

Contrapondo-se à tendência de naturalizar o estigma, alguns autores argumentam que o preconceito e a discriminação decorrem da sinergia entre fatores macrossociais, que envolvem relações de poder e dominação, como o racismo, o sexismo, o classismo e a homofobia, e fatores microssociais, como aspectos culturais e subjetivos, na configuração das relações entre os sujeitos. Segundo essa perspectiva, o estigma teria a função de aprofundar processos de desigualdade social, tornando-os mais específicos em relação a determinados grupos e subgrupos (PARKER; AGGLETON, 2003; PHELAN et al., 2008; MONTEIRO et al., 2003). Ou seja, os processos de estigma, preconceito e discriminação resultam de um modo particular de interação entre contextos culturais e condiçôes socioeconômicas e políticas. Para compreendê-los e enfrentá-los, é preciso ir além da descrição das experiências individuais e levar em conta os marcadores sociais da diferença, que historicamente têm produzido desigualdades de classe social, gênero, raça/etnia, diversidade sexual, entre outros, e os mecanismos pelos quais estes se reproduzem no âmbito das relações interpessoais.

Este enfoque permite maior aproximação das dinâmicas sociais responsáveis pela origem e manutenção de determinados grupos sociais à margem dos bens simbólicos e materiais nas sociedades contemporâneas. Adicionalmente, contribui para o entendimento das implicações dos estereótipos de gênero, da homofobia, do racismo e demais formas de violação dos direitos humanos nas diferentes esferas da vida, fornecendo subsídios para as ações voltadas para a garantia de suporte legal e social aos sujeitos estigmatizados, de modo a reduzir sua vulnerabilidade a diferentes agravos.

\section{Reprodução social, poder e estigmatização}

O pressuposto de que as visões e as práticas sociais dos sujeitos resultam da combinação entre as lógicas simbólicas, posições socioeconômicas e condições de existência nos remete à relação entre o indivíduo e as estruturas sociais na análise das práticas cotidianas, assim como para a discussão dos aspectos subjetivos e objetivos das manifestações culturais. $\mathrm{Na}$ busca de proposições 
teóricas capazes de superar a premissa da determinação da estrutura social sobre o indivíduo (objetivismo) e as abordagens fenomenológicas centradas na experiência individual (subjetivismo), Bourdieu (1992) sugere a análise das relações dialéticas entre o ator e a estrutura social. Segundo essa visão, as práticas sociais não são o produto da obediência às regras "objetivamente adaptadas a seu fim sem supor a intenção consciente dos fins e o domínio expresso das operações necessárias para atingi-los, conforme propóe o objetivismo; nem tampouco resultam de uma ação organizada de um regente", como proposto na perspectiva subjetivista (BOURDIEU, 1994a, p. 61, 65). Essa formulação pode ser compreendida por meio do conceito de habitus, definido como um sistema de disposiçôes, decorrente de experiências passadas, duráveis e transponíveis que gera as percepções e ações dos indivíduos.

De acordo com esse enfoque, o mundo social é um espaço multidimensional caracterizado por uma rede de "campos", com dinâmicas e lógicas próprias, investidos de capital (poder), econômico ou cultural. A interação entre os "campos" é marcada por disputas que visam manter ou mudar a configuração dessas forças. A classe dominante, por ter mais acesso e possuir mais capital, tende a controlar os campos investidos de poder e estabelecer uma distinção social em relação às outras classes. Diferentes posições sociais no interior dos "campos" indicam variações de estilos de vida. O gosto - escolhas e preferências dos indivíduos, aparentemente voluntárias - forma a base do estilo de vida e das práticas sociais, funcionando simbolicamente como sinais da posição social, status e distinção. Assim, o estilo de vida guarda estreita relação com a posição social, conforme evidenciam os levantamentos das preferências e práticas culturais entre as classes populares, médias e superiores (BOURDIEU, 1994b).

Tal perspectiva sugere a forte influência das condições objetivas na formação das disposições orientadoras das práticas. Entretanto, Bourdieu (1992) argumenta que sua proposição se contrapõe aos modelos circulares (estruturas produzem habitus, que determinam práticas, que reproduzem estruturas) pelo fato de ser um sistema aberto de disposições, durável, mas não eterno. Embora reconheça que os estímulos exteriores são percebidos a partir de experiências anteriores e que as experiências originais são prioritárias nesse sistema de disposições, o autor sustenta que um mesmo habitus pode produzir práticas distintas, pois é um sistema de potencialidades constituídas na relação com as estruturas, capaz 
de reproduzi-las ou modificá-las. Quer dizer, a concepção da prática enquanto resultado da relação dialética entre a estrutura objetiva (definidora das condiçōes sociais de produção do habitus) e a situação (espaço social de exercício do habitus) revela o sentido de continuidade e regularidade, mas aponta para a possibilidade de mudança (BOURDIEU, 1992).

Conforme proposto por Parker e Aggleton (2003, p. 18), as premissas de Bourdieu, somadas às contribuições de Foucault e Gramsci, fornecem um instrumental teórico para a compreensão dos mecanismos de poder e reprodução das práticas sociais relacionadas aos processos de estigmatização, haja vista que o estigma atua na interseção entre cultura, poder e diferença. Para os autores, a articulação entre essas categorias pode ser feita a partir de três conceitos: violência simbólica, modo como os sistemas simbólicos promovem o interesse de grupos dominantes e pelos processos de distinção e hierarquia entre os grupos, sem que haja forte resistência e consciência dos grupos dominados (apud BOURDIEU, 1977, 1984); hegemonia, que resulta da interação de forças políticas, sociais e culturais que legitimam as estruturas sociais de desigualdade entre os indivíduos, grupos e instituições (apud GRAMSCI, 1970); regimes de poder relacionados aos processos históricos de produção de conhecimento e suas implicações para o controle social dos indivíduos (FOUCAULT, 1977). Nas palavras de Parker e Aggleton (2003, p. 19):

Stigma operates not only in relation to difference [...], but even more clearly in relation to social and structural inequalities [...] stigmatization [...] is part of complex struggles for power that lie at the heart of social life. [...] Notions of symbolic violence and hegemony also help us to understand how it is that those who are stigmatized and discriminated against in society so often accept and even internalize the stigma that they are subjected to.

Este artigo visa analisar as concepções e experiências sobre preconceito e discriminação de um grupo de mulheres e homens jovens frequentadores de espaços de sociabilidade em dois bairros no Rio de Janeiro. Objetiva-se apreender os processos sociais e culturais que orientam as visões, as vivências $\mathrm{e}$ as reações desses jovens frente às diferentes formas de discriminação e preconceito na vida cotidiana. Tem-se o propósito de indagar se o grupo opera predominantemente a partir de processos de naturalização das características de inserção social do sujeito, ou se as manifestações discriminatórias são vinculadas à reprodução das dinâmicas sociais de produção e manutenção das hierarquias e desigualdades sociais. 


\section{Percurso metodológico}

Como parte de uma pesquisa mais ampla, ${ }^{2}$ foram realizadas observações etnográficas em espaços de sociabilidade juvenil em dois bairros da cidade do Rio de Janeiro (Madureira e Lapa) e entrevistas com 24 jovens entre 18 e 26 anos, autoclassificados como homossexuais, bissexuais ou heterossexuais, e autodefinidos como negro, branco, pardo, moreno, entre outros, inseridos em contextos socioeconômicos diversificados. As entrevistas tiveram como foco as dinâmicas de sociabilidade, as experiências sexuais e afetivas, as concepções e vivências sobre preconceito e discriminação.

A seleção dos bairros de Madureira e Lapa decorreu da existência de circuitos de interação homo, bi e heterossexual, e de contatos de membros da equipe com informantes locais. A coleta de dados foi realizada por um grupo de pesquisadores formado por mulheres e homens jovens, de diferentes cores/raças e orientação sexual, ${ }^{3}$ treinados e supervisionados durante o trabalho de campo.

O bairro de Madureira fica a 50 minutos do centro da cidade e conta com uma boa rede de transporte coletivo, atraindo moradores de bairros próximos e de municípios periféricos A utilização das praças, ruas e calçadas como áreas de lazer noturno permite que jovens de baixo poder aquisitivo encontrem divertimento barato. A maioria da população que reside ou circula no bairro é constituída de pardos $^{4}$ e pretos. A pesquisa em Madureira foi realizada em dois espaços distintos, um, conhecido com "Rua", onde jovens gays, lésbicas e simpatizantes (GLS) se encontram. O outro, o baile "Charme", é frequentado por um público adepto da cultura negra e da black music. No "Charme" predominam homens e mulheres negros/pretos, reconhecidos por suas performances na dança e pelo estilo de vestuário e penteado.

A Lapa é um bairro tradicional do centro da cidade em termos de boemia e lazer noturno. A facilidade de acesso por meio de transporte público possibilita a circulação de pessoas oriundas de diferentes regiôes da cidade e de municípios próximos. Os jovens se distribuem pelas calçadas, bares e boates em função de gostos musicais, estilos e poder aquisitivo. O bairro atrai pessoas de todos os tipos, havendo maior concentração de brancos, se comparado à Madureira. $\mathrm{Na}$ Lapa, a demarcação de fronteiras a partir da orientação sexual ou da cor/raça foi pouco expressiva, com exceção de dois espaços de interação homoerótica masculina, como as boates Cine Ideal e Cabaret Casanova. 
As aproximaçôes entre a equipe de pesquisa e os jovens foram feitas a partir de contatos diretos ou mediadas pela rede de conhecidos dos pesquisadores que frequentavam o local, favorecendo a criação de laços de confiança. As entrevistas foram gravadas e as observações etnográficas registradas no diário de campo. Foram respeitados os princípios éticos de participação voluntária e assegurado o sigilo dos dados e o anonimato dos entrevistados. O estudo foi registrado no CONEP (CAAE 0051.0.011.0000-8) e aprovado pelo Comitê de Ética da Fiocruz (Protocolo no 488).

Após a transcrição e leitura das 24 entrevistas e da criação e revisão dos códigos usados no processo de codificação, os dados foram inseridos no programa ATLAS/ti (Visual Qualitative Data, Analysis Management Model Building). A interpretação dos dados foi feita por meio da técnica de análise temática, centrada na identificação dos núcleos de sentido relativos às concepções e vivências de preconceito e discriminação que emergiram a partir das seguintes questôes deflagradoras: você já presenciou alguma situação de preconceito? Você tem algum preconceito? Você já agiu de maneira preconceituosa em alguma situação? Já conheceu algum caso de discriminação? Você já sofreu algum tipo de discriminação?

\section{Resultados}

Os/as jovens entrevistados/as em Madureira, em geral, residiam em bairros de menor poder econômico, referindo renda de um a quatro salários mínimos, e escolaridade variando entre níveis médio e superior incompletos. Na Lapa, a maioria morava em bairros de maior poder aquisitivo, sendo a renda mensal relatada de três a dez salários mínimos. Neste grupo notou-se maior frequência de acesso à educação superior e dedicação à formação profissional acadêmica. Com relação à autoclassificação da cor/raça, em ambos os grupos houve variação dos termos utilizados como negro, branco, mestiço, tudo, moreno, chocolate claro, pardo, indicando a existência de um amplo gradiente de cores.

\section{Preconceito e discriminação: definições e práticas}

Parte dos/as entrevistados/as define o preconceito como algo inerente ao ser humano, uma atitude "instintiva" relacionada a alguma diferença percebida no outro. Ter preconceito é considerado distinto do ato de discriminar, entendido 
como uma ação direta de desqualificação do outro. Entretanto, é admitido que o preconceito oriente o sujeito em suas escolhas.

Eu acho que o preconceito é inerente ao ser humano. "Não tenho preconceito nenhum, nunca" é mentira. Uma hora você vai se deparar com a diferença, [...] o ser humano não consegue lidar com a diferença assim, sabe? [...] por exemplo, você vai ver alguém aleijado na rua, é óbvio que você não vai ficar sacaneando a pessoa, mas você vai bater o olho diferente naquela pessoa. Eu, por exemplo, não ia me relacionar com uma pessoa sem braço, isso é um preconceito (mulher, parda, homossexual, 24 anos, Lapa).

A distinção entre o preconceito, algo sentido ou pensado, e a discriminação, entendida como ato, não é problematizada, embora o resultado de ambos os processos seja o alijamento do sujeito do acesso a determinadas interações ou bens sociais. Do mesmo modo, não é problematizada a definição da característica que institui a ideia da "diferença”. Apesar de serem apoiadas em práticas sociais que resultam na exclusão do outro, os depoimentos não revelam uma reflexão sobre as razões pelas quais certos sujeitos, e não outros, são escolhidos como objeto dessas práticas. Quer dizer, para os agentes, o preconceito não está relacionado à (re)produção do estigma, dispositivo social que dá suporte à discriminação e exclusão social. No entanto, como bem apontaram Phelan et al. (2008), não se pode separar os dois processos, já que a existência do estigma se confirma nos processos de discriminação e vice-versa.

A não problematização do preconceito aponta para a naturalização deste processo. Ademais, na mesma vertente de ser considerado como inerente ao ser humano, o preconceito é entendido como uma resposta "automática" ("sem querer”) no momento em que o sujeito se depara com algo estranho, não familiar, conforme referido abaixo:

Acho que é até um pouco automático na nossa cabeça, o fulano mora em Bangu, você já pensa, fulano é aculturado ou tem uma cultura que não é compatível com a sua. [...] nunca taxei alguém, mas essas coisas acabam passando pela minha cabeça (mulher, branca, heterossexual, 24 anos, Lapa).

Para outra entrevistada, existe uma distinção entre preconceito e "estranhamento", descrito como uma justificativa plausível para as reações negativas em situações nas quais o sujeito não está acostumado. Aparentemente, neste caso, a distinção reside no fato de o preconceito envolver sentimentos negativos prévios a pessoas ou grupos, enquanto o estranhamento se relaciona à surpresa frente a uma situação não habitual: 
Já vi pessoa num lugar, por exemplo, fazer cara feia porque tinha pessoas se beijando do mesmo sexo, achar estranho. Não sei se é preconceito ou se é achar estranho (mulher, branca heterossexual, 23 anos Lapa).

Mesmo considerando que é "natural" do ser humano ter preconceito ou reaçōes negativas frente ao estranho, os/as entrevistados/as recusam esta ideia, alegando que suas escolhas derivam dos seus gostos ou preferências. Esta operação de pensamento (ilustrada na fala abaixo), que leva o sujeito a agir e a fazer escolhas sem questionar as origens de determinados atos ou preferências, se assemelha à concepção de habitus de Bourdieu referida anteriormente:

Eu não acho que seja preconceito, mas eu não gosto muito de sair com pessoas negras [...]. Vejo como uma preferência física, só isso. Não é me valorizando, mas eu sou muito humano, penso muito nos outros. Me ponho muito no lugar das pessoas. Não gosto de maltratar velhinho, pessoas com deficiência, não tenho preconceito não. Nem de raça, nem de credo (mulher, parda, homossexual, 24 anos, Madureira).

Segundo os/as entrevistados/as, preconceito e discriminação não são as mesmas coisas, e as preferências ou estranhamento são entendidos como reações justificáveis frente a um "outro", cuja alteridade é construída em relação às diferenças físicas, socioeconômicas ou do comportamento sexual que remetem à ideia de "normalidade". Sem identificar que tais diferenças revelam hierarquias e desigualdades sociais, o incômodo e/ou desejo de ficar distante deste "outro", tende a ser naturalizado, conforme apontado por Monteiro e Cecchetto (2009) e Bastos et al. (2010).

Nas explicaçôes sobre os fatores envolvidos no preconceito e na discriminação, verifica-se ainda uma relação entre aparência (vinculada à cor/raça e/ou vestuário) e o comportamento do sujeito, definido como "postura". Ou seja, a aparência pode ser relativizada em função de um comportamento que confirma se o sujeito está de fato marcado por suas características de inserção social, orientação sexual e gênero, ou se foi capaz de apagar estas marcas e tornar-se "igual" aos outros. $\mathrm{O}$ depoimento abaixo exemplifica este ponto:

Tenho [preconceito] social, é por aí mesmo, social. Não é a cor do cara, quando o cara entra no ônibus não é a cor dele que vai me deixar bolado, é a postura. Como ele está ali se colocando na situação do ônibus, começa a falar mais alto, começa a querer... (homem, pardo, heterossexual, 24 anos, Lapa).

O mesmo entrevistado prossegue, sugerindo que, em parte, a denominada "postura" parece estar relacionada ao entrecruzamento entre diferentes marcadores de desigualdade: 
Eu percebo assim, que a população pobre, negra também, é constantemente intimi-

dada [...]. O cara é negro, ele entra num ônibus, os caras vão olhar para ver se ele é ou não [bandido]. Eu ficaria revoltado [...] eu acho que eu não sofro tanto isso porque eu passo a impressão que tenho uma condição de grana melhor, então as pessoas não têm tanto medo. Mas preconceito social é uma parada absurda, junto do racial (homem, pardo, heterossexual, 24 anos, Lapa).

A percepção da intercessão dos diferentes marcadores sociais de desigualdade, atuando com intensidades distintas em função de situações específicas também aparece em outro depoimento:

Eu vejo muito é o preconceito social, de classes. Está muito ligado, uma forte correlação da classe com a cor [...] O racismo em si, ele é bem mais da parte dos que são socialmente superiores, economicamente superiores (homem, branco, heterossexual, 23 anos, Lapa).

Neste outro exemplo, um jovem autoclassificado como homossexual relata sua objeção a se relacionar com homossexuais cujo comportamento evidencia sua orientação sexual. Aqui a origem do preconceito não é a classe social ou a raça/ cor, mas os modelos de masculinidade e heterossexualidade. Chama atenção a possibilidade de as pessoas não heterossexuais omitirem esta condição nas suas interaçôes sociais, como forma de se defender do preconceito, o que é limitado para as pessoas não brancas e mais pobres. As estratégias acionadas pelos sujeitos pra se protegerem dos distintos tipos de preconceitos foram discutidas por Pinho (2007), ao argumentar que homens gays, brancos e de classe média são menos afetados por preconceitos, incluindo a homofobia, que os não brancos pertencentes às classes populares.

Eu não gosto de amigos gays muito afetados. Muito afeminados eu não consigo conviver muito bem. Talvez isso seja um preconceito. Com negros não tenho problema nenhum, mas não seria amigo de uma travesti. Não seria por que, pô!, eu almoçando com o pessoal do trabalho e encontrar, sabe, no centro da cidade, e me cumprimentar e eu não ia... Ia gerar uma situação meio chata, assim (homem, branco, homossexual, 25 anos, Lapa).

Ainda nesta direção, nota-se que o preconceito, expresso pela evitação ou desconforto do contato com determinadas pessoas, é admitido mesmo que não pareça ter uma razão lógica; como indicado na fala a seguir, na qual o entrevistado faz uma assimilação entre racismo e preconceito, fazendo supor que o racismo, entendido como discriminação racial, seria uma expressão mais condenável do que a homofobia: 
Fico p... da vida quando estão me paquerando. Daí já rola um preconceito. Até te explicando, parece que eu tenho racismo contra homossexual mas eu não tenho, mas é complicado (homem, pardo, heterossexual, 26 anos, Madureira).

Outro fator identificado como gerador de preconceito diz respeito à formação de um "olhar" pré-condicionado, fruto dos valores adquiridos no processo de socialização na família, escola e com amigos. Não há um questionamento sobre a origem desses valores, nem uma reflexão sobre as razôes de sua preservação e reprodução ao longo da vida.

[o que gera o preconceito] não são as diferenças, são as maneiras que você vê as diferenças. [...] Acho que a pessoa é preconceituosa por falta de conhecimentos, esclarecimento, às vezes até criação e assim vai (homem, branco, heterossexual, 23 anos, Lapa).

\section{Vivências de discriminação: quando o agente se torna objeto}

Contrapondo-se à visão mais naturalizada do preconceito e da discriminação, que domina os relatos de suas experiências como agentes, quando situados na posição de quem é afetado pelos processos de estigmatização, os/as entrevistados/ as indicam uma percepção mais aguda da interação dos diversos marcadores sociais de desigualdade na produção do estigma:

Se for pensar preconceito racial, até que não, porque eu já estou meio que inserido à classe, a questão racial meio que assim não aparece, todo mundo meio que se parece. Agora, em termos de [...] quando eu fui pra Zona Sul algumas vezes, eu me senti um pouco constrangido [...] por exemplo, quando eu fui na PUC, é uma realidade completamente diferente, as pessoas olhavam, assim, todo mundo branco, feliz (homem, 21 anos, heterossexual, pardo, Madureira).

[...] o preconceito por ser mulher, acho que acontece muitas vezes implícito [...] Aquele negócio que está atrelado a nossa cultura machista. De algumas pessoas acharem que você é menos inteligente, tem menos potencial para certas coisas, para certos trabalhos, por ser mulher. Teve uma situação que eu me lembro, [...] a gente estava na oitava série e dali todo mundo ia fazer concurso pra escolas públicas de segundo grau. E como a nossa escola era deficiente em algumas coisas [...] a diretora teve a preocupação de incrementar nossas aulas, fazer aulas aos sábados para preparar os alunos. Nisso ela conseguiu apoio de um curso preparatório [...] alguns professores voluntários. Só que com uma condição, eles só davam aula para homem e aí acabou que a diretora aceitou [...] mas conseguiu convencer os professores da própria escola a darem aula para as meninas aos sábados também, paralelo. Então ficou uma turma de meninos e uma turma de meninas, aos sábados, e de segunda a sexta, todo mundo era junto. No final das contas nenhum menino passou. Mas eu me lembro que isso me marcou muito, eu fiquei muito revoltada. E me deu um gás para estudar mais [...] eu 
fui a única que passou [...]. Eu me orgulhei de ser mulher nesse momento... (mulher, branca, heterossexual, 24 anos, Lapa).

Todavia, tal percepção não resulta em um questionamento maior sobre a origem e a dinâmica destes processos, na perspectiva de um enfrentamento deste tipo de prejuízo social. Ao contrário, para alguns dos/as participantes, uma forma de lidar com o preconceito é a autoexclusão, ao se buscar evitar as situações onde este possa se explicitar (BECKER, 2008), conforme o depoimento abaixo:

Quando você anda do lado de uma pessoa mais clara, rica... Não tem aquelas pessoas metidas? Você fica até com receio de andar do lado da pessoa... Pelo menos acontece comigo. A maioria das vezes eu ando só. Até dentro do ônibus, de repente, você não está bem vestido, você está à vontade, está calor, aí senta do lado dessa pessoa, ela vai achar que eu sou ladrão. Para não acontecer isso eu vou ficar em pé ou sentar ao lado de uma pessoa da minha cor, isso acontece (homem, negro, 26 anos, heterossexual, Madureira).

Esta postura é criticada por outro entrevistado ao referir à vitimização ou falta de ação por parte dos negros que, de alguma maneira, torna este grupo mais vulnerável às posturas discriminatórias:

Muitas vezes nós somos culpados porque a gente não corre atrás dos nossos direitos, a gente não abre a boca. Mesmo quando a coisa é pequena, às vezes acontece comigo, está passando, uma senhora te vê e segura a bolsa, você vê, você não é cego, você percebe. $\mathrm{O}$ dia que a pessoa se conscientizar, o dia que você chegar e falar, Pô, minha senhora, o que isso? Chegar e falar, está pensando que eu vou roubar a tua bolsa? (homem, heterossexual, pardo, 26 anos, Madureira).

Ou seja, ao mesmo tempo em que existe um reconhecimento do preconceito como fruto da desigualdade social, é cobrada do sujeito uma reação individual de enfrentamento, numa visível contradição entre as dimensões macro e microssociais, reconhecida com um dos obstáculos para a construção da equidade (SILVA, 2012). Outra perspectiva de enfrentamento - igualmente caracterizada como uma atitude pessoal, centrada na adequação aos padrôes hegemônicos e não na reação - aparece no discurso abaixo:

Acho que tem o grupo das figuras que são potencialmente discriminadas assim, $a$ priori, negro, lésbica, mulher... O que eu posso fazer, é só aceitar e procurar ter uma conduta. Eu tenho que ter consciência que para algumas pessoas isso é o cúmulo... Toda errada (mulher, parda, 24 anos, homossexual, entrevistada na Lapa).

Admitindo ser extremamente vulnerável ao estigma, por acumular várias características marcadas pelo preconceito, ela aponta como alternativa a adoção 
de uma conduta exemplar que a exima de outras críticas. Tal visão tende a legitimar os padrôes hegemônicos e as hierarquias sociais.

\section{Discussão}

Por meio dos depoimentos, foi possível apreender alguns dos processos sociais e culturais que orientam as visões, vivências e reações dos/das jovens frente às diferentes formas de discriminação e preconceito na vida cotidiana. Foi observado que estes processos se baseiam numa perspectiva de naturalização na qual o preconceito em relação a certas características ou comportamentos identificados como "diferentes" é considerado natural.

Segundo os/as entrevistados/as, seus preconceitos e ações discriminatórias não estão relacionados a características específicas do sujeito, mas a uma tendência humana de se afastar do que é estranho. Uma variante deste tipo de explicação é a concepção do preconceito como decorrente da reprodução de comportamentos e hábitos mentais aprendidos ao longo do processo de socialização e educação formal, introjetados pelo sujeito por meio de práticas cotidianas de intimidação e exclusão social. Tais práticas são associadas principalmente às hierarquias de cor/ raça e classe e se expressam a partir da circulação do sujeito por espaços distintos do seu lócus social de origem, o que favoreceria a visibilidade das diferenças e reforçaria a dimensão contextual dos processos de discriminação, assinalados por Monteiro e Cecchetto (2009) e Bastos et al. (2010).

Nota-se a ausência de uma reflexão sobre o processo que institui características específicas como uma forma de diferenciação, e a relação entre a produção de diferenças e desigualdades. Entretanto, não por acaso, os/as entrevistados/as consideram "natural" ter algum preconceito em relação aos mais pobres, menos brancos, que portam alguma deficiência ou são homossexuais, e principalmente os que associam duas ou mais destas características. Ou seja, populações, grupos ou indivíduos já situados em posições de desvantagem social.

De acordo com estes resultados, o processo de naturalização do preconceito produzido e reproduzido pelos informantes ocorre a partir de dois movimentos simultâneos: num primeiro, seria tomada como "natural" (inquestionável) a ação de evitar a interação com determinado sujeito, a partir de suas características; num segundo, haveria o apagamento de qualquer reflexão a respeito das razóes 
pelas quais aquele outro é tomado como signo de uma alteridade incômoda, negativa ou perniciosa.

Num aparente contraste com esta posição, os relatos das vivências de discriminação parecem evidenciar maior percepção de processos sociais de exclusão e manutenção de privilégio de certos grupos, com base na valoração negativa de alguns atributos dos sujeitos. No entanto, a percepção de um processo mais amplo de produção de desigualdades não é suficiente para ir além da compreensão do processo como "natural", inexorável. Observa-se nos depoimentos que a discriminação não é pensada, de forma geral, como um problema da sociedade, e sim como uma contingência frente à qual os sujeitos afetados devem buscar alternativas. Assim, as alternativas dos/as entrevistados/ as de buscar respostas que os protejam dos danos relacionados a sua exposição ao preconceito não ultrapassam as ações de caráter individual, seja na perspectiva de dissimulação, evitação do contato ou do confronto interpessoal.

Nas falas, as manifestações de preconceito se configuraram como uma limitação do acesso às interações sociais e circulação em alguns espaços para aqueles que as sofrem. Contudo, na maioria dos casos, tal desvantagem social suscita uma reação resignada e de autodefesa, sugerindo o mecanismo de introjeção do preconceito, como apontado por Bourdieu (1999, p. 45-55). Ressalte-se que a introjeção do preconceito é um poderoso mecanismo de reprodução social das práticas discriminatórias, que acaba por reforçar a perspectiva naturalizante que permite sua perpetuação.

No plano das práticas sociais, nas quais o preconceito e a discriminação se materializam, os relatos sugerem um reconhecimento também parcial. Com base em concepçôes sobre reaçôes inerentes aos seres humanos, gosto, hábito ou educação, os depoimentos indicam a ausência de uma reflexão sobre a origem e a historicidade desses processos e suas consequências na exclusão de sujeitos portadores de certas características do acesso a espaços e interações sociais; como se a discriminação fosse uma questão de âmbito interpessoal, associal e anistórica.

Cabe levar em conta que a abordagem direta do tema "discriminação" junto aos informantes, a partir de perguntas específicas, pode gerar discursos críticos e "politicamente corretos", em que não são referidos os atributos do outro, considerados como justificativa da exclusão, e sim particularidades 
do sujeito (BASTOS et al., 2010). Esta tendência se confirma no relato das experiências pessoais, seja no papel de agente ou objeto de discriminação, em geral minimizadas enquanto um problema social grave. Estes achados convergem com outros estudos sobre estigma e discriminação, que apontam os limites do foco nos relatos sobre conceitos e experiências, sem uma abordagem mais densa dos fatores estruturais que os determinam como referido na introdução.

Embora os danos ocorram independentemente do tipo de preconceito sofrido, seja de raça, gênero, sexualidade ou classe, existe maior potencial danoso quando experimentados simultaneamente. Esta afirmativa converge com a observação empírica, apoiada nas reflexões dos informantes, de que existe uma sinergia entre os eixos sociais de produção de desigualdade, embora não haja simetria ou homogeneidade na intensidade em que cada fator contribui na produção do estigma. Em determinados contextos ou situações, a inserção numa determinada classe social pode reduzir ou potencializar os efeitos do racismo, sexismo e da homofobia, da mesma forma que ser branco ou heterossexual pode atenuar os efeitos da discriminação relacionada à pobreza.

Outro trabalho sobre a dinâmica de circulação desse mesmo grupo de jovens entrevistados aponta que ser ou não morador de uma ou outra localidade, mais especificamente da Zona Sul do Rio de Janeiro, produz inferências sobre modos de ser, saberes e comportamentos sociais que contrastam com os da Zona Norte, sugerindo uma demarcação das fronteiras entre "nós" e "eles" como expressão de relações sociais (MONTEIRO et al, 2010). A autoexclusão dos sujeitos de ambientes percebidos como fora de sua realidade pode indicar uma disposição social interiorizada, uma forma de reconhecimento antecipado do preconceito, nos termos de Bourdieu (1994). A percepção da oposição entre grupos de status mais elevado e aqueles em posição considerada inferior, aparece no relato dos entrevistados, sob uma perspectiva de naturalização que pervade a produção acadêmica, dificultando avanços teórico-metodológicos que permitam um aprofundamento das circunstâncias sociais diversas nas quais o estigma e a discriminação são produzidos e reproduzidos (ELIAS; SCOTSON, 2000).

\section{Considerações finais}

Considerando que a pesquisa da qual os dados sobre discriminação e preconceito foram extraídos para a elaboração deste artigo não tinha como objetivo central 
a análise do tema, é preciso salientar as limitaçōes metodológicas impostas ao

processo de análise e interpretação dos dados. Contudo, foi considerado que os depoimentos colhidos acerca das experiências individuais relativas ao preconceito e a discriminação - vividos, presenciados ou manifestados - e as formas de enfrentamento permitiram apreender as concepções relativas a tais eventos, de forma suficiente para atender aos objetivos pretendidos para esta reflexão.

Por meio dos relatos dos/das entrevistados/as, mulheres e homens jovens de diferentes inserções sociais, cores/raças e orientação sexual, foi possível identificar a perspectiva de naturalização do preconceito e da discriminação, e as formas e circunstâncias nas quais as experiências de discriminação atuam e são apreendidas pelos sujeitos. Tal enfoque converge com as reflexôes da literatura acerca da necessidade de se contemplar a influência das interaçôes entre os diversos eixos sociais de produção de desigualdade na construção do estigma, do preconceito e da discriminação, e na sua naturalização; bem como na definição das formas de enfrentamento dos processos de estigmatização.

Como assinalado, há uma crítica recente sobre o desenho metodológico empregado nos estudos sobre os processos de estigma/discriminação associados às condições de vida e saúde, sinalizando a importância de um esforço na articulação dos fatores macrossociais (culturais, políticos, socioeconômicos) às experiências individuais (cognitivas, psicológicas) de discriminação. Nesse sentido, a abordagem dos sujeitos a partir de suas posições e identidades sociais (classe, gênero, raça/cor, orientação sexual) permite aprofundar a reflexão sobre as repercussões das relações de poder e dominação presentes na sociedade e a desigualdade estrutural enquanto elementos que modelam subjetividades, conferindo sentidos distintos às experiências de discriminação e à apreensão dos sujeitos sobre a sua vulnerabilidade. ${ }^{5}$

\section{Referências}

ALLPORT, G. The Nature of the Prejudice. Cambridge: Addison Wesley, 1954. 537p.

ARMIJOS, R.; WEIGEL, M.; QINCHA, M. et al. The meaning and consequences of tuberculosis for an at-risk urban group in Ecuador. Rev Panam Salud Publica, v. 23, n. 3, p. 188-197, 2008.

BASTOS, J.; GONÇALVES, H.; FAERSTEIN, E. et al. Experiências de discriminação entre universitários do Rio de Janeiro. Revista Saúde Pública. São Paulo, v. 44, n. 1, p. 28-38, 2010. 
BECKER, H. Outsiders. Estudos de sociologia do desvio. Rio de Janeiro, Zahar, 2008. 232p. BOURDIEU, P. A dominação masculina. Rio de Janeiro: Bertrand Brasil, 1999. 160p. . Esboço de uma teoria prática. In: ORTIZ, R. (Org.). Pierre Bourdieu. São Paulo: Ática, 1994a. p. 46-81.

. Gostos de classes e estilos de vida. In: ORTIZ, R. (Org.). Pierre Bourdieu. São Paulo: Ática, 1994b. p. 82-121.

. Interest, habitus and rationality. In: BOURDIEU, P.; WACQUANT, L. (Org.). An Invitation to Reflexive Sociology. Chicago: The University of Chicago Press, 1992. p. 115-140.

ELIAS, N.; SCOTSON, J. L. Os estabelecidos e os outsiders: sociologia das relaçôes de poder a partir de uma comunidade. Rio de Janeiro: Jorge Zahar, 2000.

FRY, P. A persistência da raça: ensaios antropológicos sobre o Brasil e a África Austral. Rio de Janeiro: Civilização Brasileira, 2005. 348 p.

GATO, J.; CARNEIRO, N.; FONTAINE, A. Contributo para uma revisitação histórica e crítica do preconceito contra as pessoas não heterossexuais. Crítica e Sociedade: revista de cultura política. v. 1, n. 1, p. 139-167, 2011.

GOFFMAN, E. Stigma: notes on the management of spoiled identity. London: Penguin, 1963. GUimarães, A. S. Preconceito e discriminação. São Paulo: Editora 34, 2004.

LINK, B.; PHELAN, J. Conceptualizing Stigma. Annual Review of Sociology, v. 27, p. 363385, 2001.

MAHAJAN, A.; SAYLES, J.; PATEL, V. et al. Stigma in the HIV/AIDS epidemic: a review of the literature and recommendations for the way forward. AIDS, v. 22, n. 2, p. 67-79, 2008. MONTEIRO, S.; CECCHETO, F. Cor, gênero e classe: dinâmicas da discriminação entre jovens de grupos populares cariocas. Cadernos Pagu, v. 32, p. 301-329, 2009.

MONTEIRO, S.; VILLELA, W.; KANUTH, D. Discrimination, stigma, and AIDS: a review of academic literature produced in Brazil (2005-2010). Cadernos de Saúde Pública, v. 28, n. 1, p. 170-176, 2012.

MONTEIRO, S.; VILLELA, W.; SOARES, P. The interaction between axes of inequality in studies on discrimination, stigma, and HIV/AIDS: contributions to the recent international literature. Global Public Health, v. 5, n. 5, p. 519-533, 2013.

PARKER, R.; AGGLETON, P. HIV and AIDS related stigma and discrimination: a conceptual framework and implications for action. Social Science \& Medicine, v. 57, p. 1324, 2003.

PARKER, R. Intersections between discrimination and health. Cadernos de Saúde Pública, v. 28, n. 1, p. 164-169, 2012. 
PHELAN, J.; LINK, B.; DOVIDIO, J. Stigma and Prejudice: One Animal or Two? Social

Science \& Medicine, v. 67, p. 358-367, 2008.

PINHO, O. Desejo e poder: racismo e violência estrutural em comunidades homossexuais.

2007. Disponível em: http://www.ciudadaniasexual.org/boletin/b15/Art_Osmundo_ Bol15.pdf. Acesso em: 10 jun. 2013.

SANSONE, L. Negritude sem etnicidade: o local e o global nas relaçôes raciais e na produção cultural negra do Brasil. Salvador: EdUFBa, 2004. 355p.

SILVA, H.; RODRIGUES, C.; LIMA, J. et al. Relação médico-paciente em oncologia: medos, angústias e habilidades comunicacionais de médicos na cidade de Fortaleza (CE). Ciênc. saúde coletiva. Rio de Janeiro, v. 16, supl. 1, p. 1457-1465, 2013.

SILVA, M. Entre a rebeldia e o conformismo: o debate com os sujeitos demandatários da política de assistência social. Tese (Doutorado em Serviço Social) - Programa de PósGraduação da Faculdade de Serviço Social da Pontifícia Universidade Católica do Rio Grande do Sul, Porto Alegre, 2012.

STOLKE, V. Sexo está para gênero assim como raça para etnicidade? Estudos Afro-asiáticos, v. 20, p. 101-119, 1999.

\section{Notas}

${ }^{1}$ O estudo de Oracy Nogueira $(1950 ; 2009)$ sobre a formação de novas identidades entre doentes de tuberculose internados, decorrentes dos processos de segregação social, antecede as contribuiçóes de Allport (1954) e Goffman (1963). Todavia, o trabalho de Nogueira é pouco referido no campo da saúde; sua obra obteve reconhecimento pelos estudos sobre relações raciais no Brasil e nos Estados Unidos que resultaram na formulação dos conceitos de "preconceito racial de marca" e "preconceito racial de origem" (NOGUEIRA, 1998).

${ }^{2}$ Projeto Relations among "race", sexuality and gender in different local and national contexts, realizado entre 2006 e 2010 em nove centros de pesquisa: USP, CLAM/IMS/UERJ, CEBRAP, IOC/FIOCRUZ, SFSU/CRGS (San Francisco), Center for the Study of Race, Politics and Culture (Chicago), AGI/UCT (Cape Town), WITS e OUT (Joanesburgo), apoio de Fundação Ford e CNPq. Pesquisadores: Laura Moutinho (coordenação geral), Simone Monteiro (Rio de Janeiro), Júlio Simões (São Paulo), Elaine Salo (Cidade do Cabo), Brigitte Bagnol (Joanesburgo), Cathy Cohen (Chicago) e Jessica Fields (São Francisco).

${ }^{3} \mathrm{O}$ trabalho de campo foi coordenado por Fátima Cecchetto e Anna Paula Vencato, e contou com a participação de Bruno Zilli, Diana Dianovsky, Felippe Mendonça, Igor Torres, Lady Cristina, Lisis Fernandes, Layla Peçanha e Silvia Aguião.

${ }^{4}$ Os termos estão citados em itálico, indicando obras citadas, categorias oficiais do IBGE (Instituto Brasileiro de Geografia e Estatística) ou autoclassificação dos pesquisadores e informantes do estudo. ${ }^{5}$ S. Monteiro e W. Villela participaram da concepção, análise dos dados e redação do artigo. P. Soares participou da análise dos dados e redação do artigo. 


\section{It is inherent to human beings! The naturalization of social hierarchies in the youth view about expressions of prejudice and discrimination}

This study aims to analyze how women and men with different social background, color / race and sexual orientation, attending social spaces in Rio de Janeiro, conceive and experience the expressions of prejudice and discrimination in everyday life. It is considered that prejudice and discrimination are part of a social process of production of social inequalities that articulates different markers (social class, gender, sexuality, race / ethnicity) and operates through naturalization acts of discriminating and being discriminated against. However, there are dissonant theoretical perspectives that view discrimination and prejudice as arising from interactions which are inherent and circumscribed to the scope of interpersonal social relations, disconnected from macro-factors. The testimonies of the study youngsters show that agents of discriminatory action avoid talking about prejudice, justifying their practices based on taste, preference or strangeness to something unusual. However, some individuals who are subject of homophobic, sexist and / or racist actions realize that these situations express an attempt to guarantee privileges to specific groups and that social class affects those involved in the events. Others believe that homophobia and racism stem from lack of knowledge and / or socialization. One notes the absence of references to political action to face discrimination. The development of studies for the apprehension of prejudice and discrimination as a complex social phenomena, associated with the (re) production of social markers of difference, can guide the actions against these processes in different social contexts.

> Key words: discrimination; prejudice; sexual diversity; color/ race; youth. 